\title{
Dorsal vaginal graft urethroplasty in female urethral stricture: a contemporary series
}

\author{
Joy Narayan Chakraborty ${ }^{1 *}$ and Nachiket Vyas ${ }^{2}$
}

\begin{abstract}
Background: Bladder outlet obstruction (BOO) is an uncommon entity in women. The incidence is only $2.7-8 \%$ of women referred for voiding symptoms. It is common to treat female urethral strictures by repeated urethral dilatations with subsequent self-intermittent catheterisation, which often leads to stricture recurrence. We aim to review the technique and outcomes of Dorsal vaginal graft Urethroplasty (DVGU) to manage urethral strictures in females.

Methods: This study is a retrospective chart review of 24 women with urethral stricture who underwent dorsal vaginal graft urethroplasty by a single surgeon. Patients were selected based on history, physical examination, uroflowmetry, urethral calibration, urethroscopy and voiding cystourethrography. We compared the pre- and postoperative values of variables such as the peak flow (Qmax), post-void residual (PVR) and self-reporting satisfaction score.

Results: Mean (range) age of the patients was 46.54 (38-55) years. The mean PVR was $6.35 \mathrm{ml} / \mathrm{s}$ and $148.12 \mathrm{ml} / \mathrm{s}$, respectively. The mean Qmax before and after surgery was $6.35-25.12 \mathrm{ml} / \mathrm{s}$, respectively $(p<0.05)$. The mean PVR decreased from $148.12 \mathrm{ml}$ (preoperative) to $41.67 \mathrm{ml}$ (postoperative) $(p<0.05)$. Before and after surgery, the mean calibration size was $12.76 \mathrm{~F}$ and $24.50 \mathrm{~F}$, respectively $(p<0.05)$. Self-reported satisfaction score (Patient Global impression of improvement) showed that five (5) patients scored 1 (very much better), sixteen (16) patients scored 2 (much better) and three (3) patients scored 3 (a little better). Three women (12.5\%) had stricture recurrence. Two of them got stabilised with initial soft dilatation, and the third women required continued self-catheterisation. Overall, the success rate was $87.5 \%$ with a mean (range) follow-up of 22.62 (12-36) months.
\end{abstract}

Conclusion: Dorsal onlay vaginal graft urethroplasty is a simple, safe and practical approach to treat female urethral stricture with a reasonable success rate. It can be considered as a first-line option for definitive repair.

Keywords: Female urethral stricture, Dorsal onlay, Vaginal graft urethroplasty

\section{Background}

Bladder outlet obstruction (BOO) is an uncommon entity in women. The incidence is only $2.7-8 \%$ of women referred for voiding symptoms [1]. Female urethral stricture (FUS) is a more rare subgroup of female $\mathrm{BOO}$ and accounts for only $4-13 \%$ cases of female BOO $[2,3]$. Compared to male strictures, this lower incidence is attributed to the shorter length, straighter course, greater anatomical mobility, and the protection provided by the bony symphysis over its entire length [4]. There is

\footnotetext{
*Correspondence: urochakraborty@gmail.com

${ }^{1}$ Apollo Hospitals, Guwahati, India

Full list of author information is available at the end of the article
}

considerable uncertainty in diagnosing FUS due to lack of agreed-upon criteria for FUS diagnosis. Urologists often use various factors such as symptoms, urethral meatal appearance, history of difficult instrumentation, urethroscopy, radiography and supportive urodynamic standards to diagnose FUS [5]. Although Urethral dilatation (UD) has long been used as the only method to treat this condition, this practice is often considered overused and unnecessary, posing a considerable expenditure on the healthcare system $[6,7]$. However, in recent years, there has been an increasing interest in female urethroplasty using multiple approaches to achieve a permanent cure. Most of the studies on female urethroplasty are of descriptive nature with small sample size. The two 
landmark developments in this field are dorsal urethrolysis by Petrou et al. [8] in 1999 and dorsal onlay autologous vaginal graft by Tsivian and Sidi [9] in 2006. In this current series, we describe the technique of dorsal onlay vaginal graft urethroplasty (DVGU) with its impact on the flow rate, symptom improvement, success rate and complications.

\section{Methods}

\subsection{Study design: retrospective review}

We identified the records of all women who underwent dorsal onlay vaginal graft urethroplasty (DVGU) from January 2015 to October 2017 by a single surgeon and retrospectively reviewed. Full Institutional Review Board approval was obtained, and informed consent from the patients was taken.

\subsection{Case selection}

Patients were selected based on a combination of subjective symptoms and objective criteria which included a) Irritative and voiding urinary symptoms, b) Poor urinary stream with a peak flow rate (Q-max) $<12 \mathrm{ml} / \mathrm{s} \mathrm{c}$ ) Urethral calibre $<16 \mathrm{~F}$ d) cystourethroscopic finding of a fixed, localised area of urethral narrowing e) Voiding cystourethrography (VCUG) showing narrow mid and distal urethra with dilated proximal urethra f) High PVR (>50 ml.) with no other bladder pathology and f) Absence of any cystocele, rectocele or genital prolapse on thorough pelvic examination.

\subsection{Perioperative evaluation}

We took a detailed history and physical examination focusing on demographic data, urinary flow, history of UTI, QOL questionnaire (Patient Global Impression of Symptom severity 'PGI-S' scale) and gynaecologic examination. Uroflowmetry, PVR (post-void residual volume), VCUG, any pertinent upper tract imaging (if available). Urethrocystoscopy with a $6.5 \mathrm{~F}$ paediatric scope was done before surgery, and the calibration size was recorded. As most of the patients were referred from other surgeons, they already had VCUG with them. We performed VCUG only on those who did not have it previously. However, we did not rely much on VCUG in our study (due to inadequate filling of the urethra with inconsistent results) and used it infrequently as a confirmatory diagnostic tool. Rather, we preferred to use Paediatric Urethroscope 6.5 F in all cases to diagnose and define the extent of the stricture. We did not use urodynamics to assess the bladder contractility and pressureflow relationship as all of our cases were straightforward with a history of multiple prior dilatations with obvious stricture found on urethroscopy and calibration. We used the self-reported symptom score using the 'PGI-S' scale (patient global impression of severity Questionnaire), a 1-item questionnaire designed to assess the patient's perception of disease severity (urinary symptoms) before any intervention or treatment. It is a 4-point scale scored as (1) Normal (2) Mild (3) Moderate and (4) Severe. After surgery, we used the self-reported PGI-I scale (patient Global impression of Improvement Questionnaire) assessment, physical examinations, urinary flow rate and PVR to assess the results. PGI-I is a 1-item questionnaire designed to evaluate the patient's impression of urinary symptoms changes after the intervention compared to the preoperative state. It is a seven-point scale scored as (1) Very much better (2) Much better (3) A little better (4) No change (5) A little worse (6) Much worse or (7) Very much worse.

\subsection{Operative description}

The patient is prepared in the modified dorsal lithotomy position under spinal anaesthesia. The operative field, including the vagina, is adequately cleaned and draped with strict aseptic measures (anus was adequately covered and excluded from the operative area). Clotrimazole vaginal pessaries are used for two days before the operation for preparation of vaginal graft harvesting. A Preliminary cystourethroscopy is done with a $6.5 \mathrm{Fr}$ paediatric cystoscope to assess the stricture length and extent. Next, a 0.038-inch size guidewire is placed inside the bladder and gradual calibration performed with sequential Teflon urethral dilators up to $16 \mathrm{Fr}$ size followed by a $16 \mathrm{Fr}$ catheter placement. This facilitates the ongoing dissection into the retropubic space. Blind calibration with urethral sound is avoided to minimise the risk of false passage. Normal saline mixed with $1 \%$ adrenaline is injected into the periurethral tissue to facilitate excellent haemostasis during dissection (Fig. 1). An inverted U-shaped incision is made dorsal to the urethral meatus from 3 to 9 O'clock position (Fig. 2). Dissection is continued in the periurethral tissue (through the vestibular membrane) staying close to the urethra with sharp scissors carefully avoiding any damage to the bulbs and the clitoral body. Dissection plane lies just dorsal to the urethra (3-9 O'clock position) towards the pubic bone without violating the urethral thickness and at the same time avoiding excessive lateral dissection and consequent bleeding. Digital palpation of the pubic bone helps to identify the proximal dissection point. This process of urethrolysis is carried through the whole extent of the stricture and little proximal to it (Fig. 3). We faced no difficulty in mobilising the urethra by using this technique, and there was no incidence of urethral injury or perforation in our series.

A full-thickness urethrotomy (including the meatus) is made dorsally (12 O'clock position) with a sharp dissecting scissor. It should be extended through and proximal 

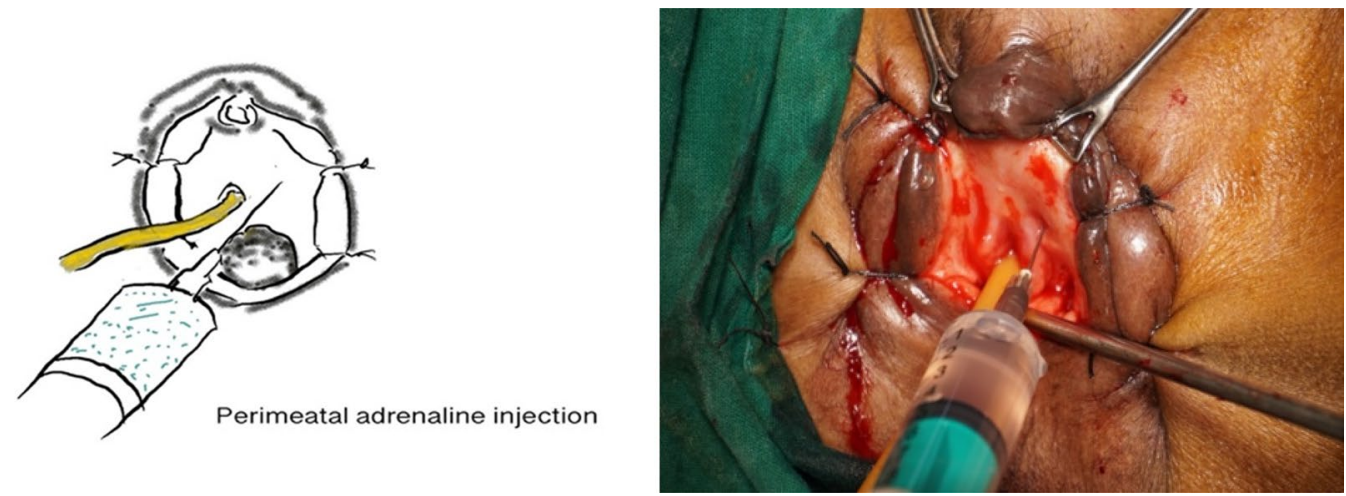

Fig. 1 Peri-meatal diluted adrenaline injection
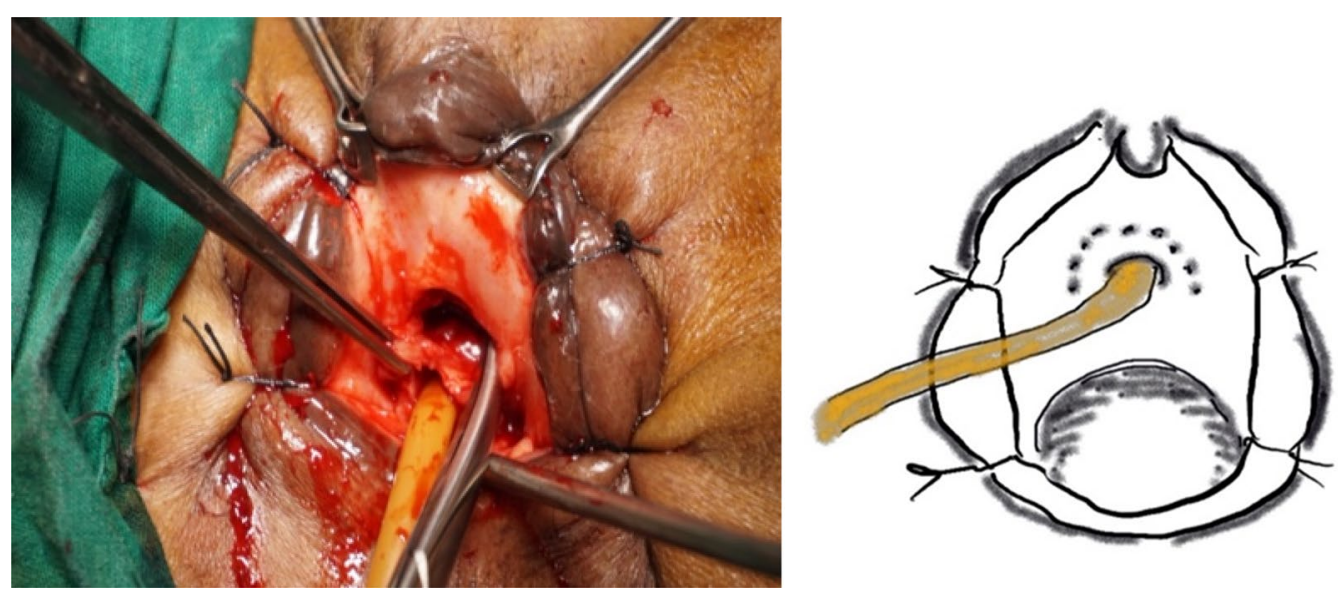

Fig. 2 Inverted U-incision from 3 to 9 O'clock position

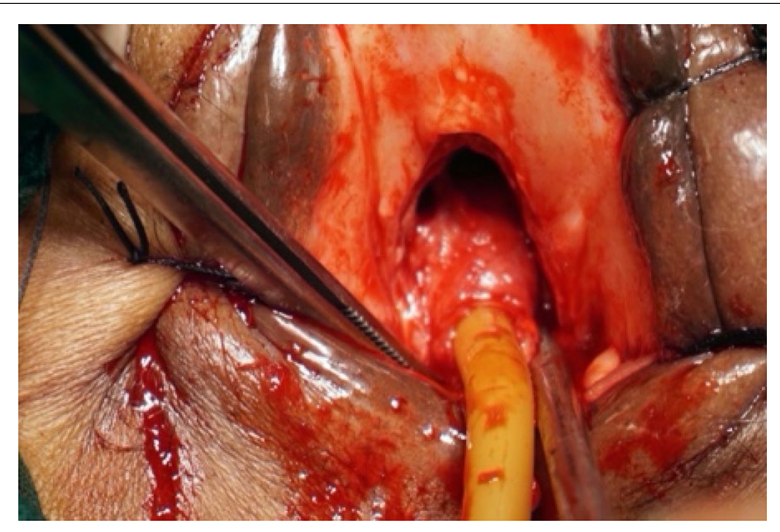

Fig. 3 Dorsal Urethrolysis

to the point of urethral stricture till healthy normal urethra is encountered (Fig. 4). Stay sutures are taken at the urethral angles to facilitate dissection. The urethral catheter is now removed, and cystourethroscopy with a $17 \mathrm{Fr}$ cystoscope is done to ascertain the lumen's adequacy and rule out any proximal stenosis beyond the incision site. This is followed by gradual calibration with Hegar's dilators up to $28 \mathrm{~F}$ to assure adequate patency.

Graft harvesting: Normal saline is injected in the left lateral wall of the vagina in the subcutaneous space, and a full-thickness vaginal wall is harvested with the dimension little larger than the estimated stricture length. The vaginal defect is closed with a running $2-0$ absorbable suture. Haemostasis is optimised, and a vaginal pack is placed. Although a significant number of our patients are from the peri- or post-menopausal group, the quality of vaginal mucosa was satisfactory, and none needed hormonal replacement before or after the procedure. Graft Anastomosis: The free graft is defatted, trimmed (according to the estimated urethral defect) and placed in normal saline. When retracted with a nasal speculum, the urethral defect looks triangular with the apex located at the 12 O'clock position. The graft is now sutured in place. The graft's mucosal 

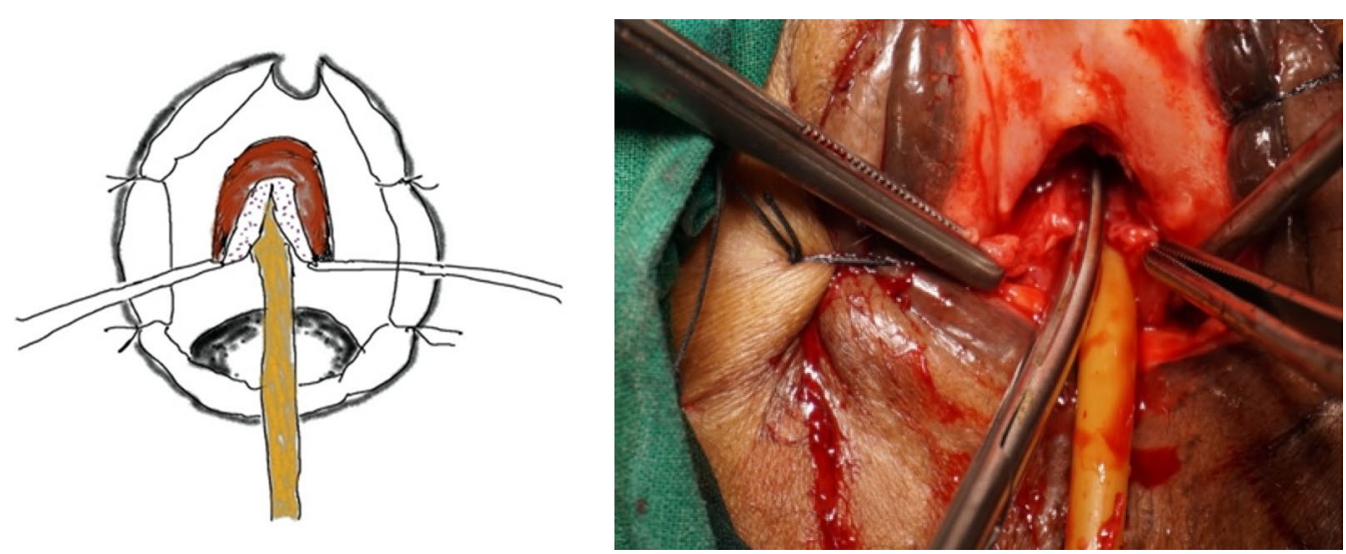

Fig. 4 Dorsal Urethrotomy (12 O'clock position)

surface should face the urethral lumen while suturing with two 4-0 polyglactin 910 (Vicryl) sutures. Each suture is placed at the apex of the urethrotomy defect (outside-in) and then onto the graft-apex (inside out) (Fig. 5). One suture is to be run on the left side, and the other suture is to be run on the right side, thus suturing the left and right margins of the graft to corresponding margins of the urethral defect (Fig. 5). In addition, two to three 3-0 polyglactin 910 (Vicryl) quilting sutures are placed centrally (at 12 O'clock position) to attach the graft to the periurethral tissue to minimise sliding especially in the first $48 \mathrm{~h}$. Quilting sutures minimises the risk of graft migration and peri-graft seroma formation, thus maximising the chances of inosculation, capillary regrowth and a better 'take.' The graft's redundant tag is trimmed and tailored at the urethral meatus to achieve a broad, slit-like meatal opening (Fig. 6). An indwelling $16 \mathrm{~F}$ Foley catheter is placed in the bladder to gravity drain. An overnight vaginal pack is introduced. At two weeks, the patient returns for catheter removal, clinical examination and soft calibration. The calibration is designed to be soft and gentle to assess the urethral calibre only and avoid any forcible dilatation. Our follow-up protocol includes an assessment of symptoms (voiding and storage), uroflowmetry and PVR estimation every three months for the first year followed by six monthly follow-up for the 2nd year and then yearly. A soft and gentle calibration was done during the first follow-up to assess the calibration size, and no attempt was made for dilatation. We did not perform routine $\mathrm{MCU}$ in all the cases.

Our definition of successful reconstruction was a postoperative Qmax greater than $15 \mathrm{ml} / \mathrm{s}$ with a self-reported improvement in symptoms and a decrease in PVR. Our definition of failure was the requirement of urethral dilatation or CISC at any time after the procedure.

We calculated the means, medians and percentages of our study variables. The principal focus was on the Qmax, PVR and QOL score pre- and postoperatively. We compared the pre- and postoperative mean and median values of Qmax and PVR using the Wilcoxon matchedpairs signed-rank test with the associated $p$ values). A $P$
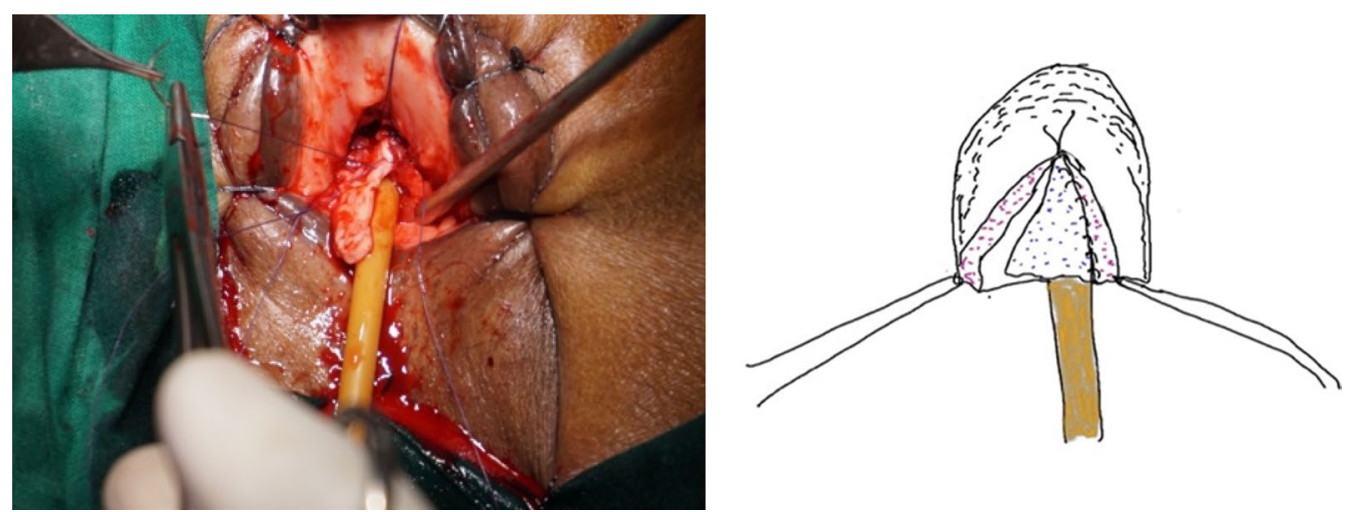

Fig. 5 Vaginal graft suturing in progress 

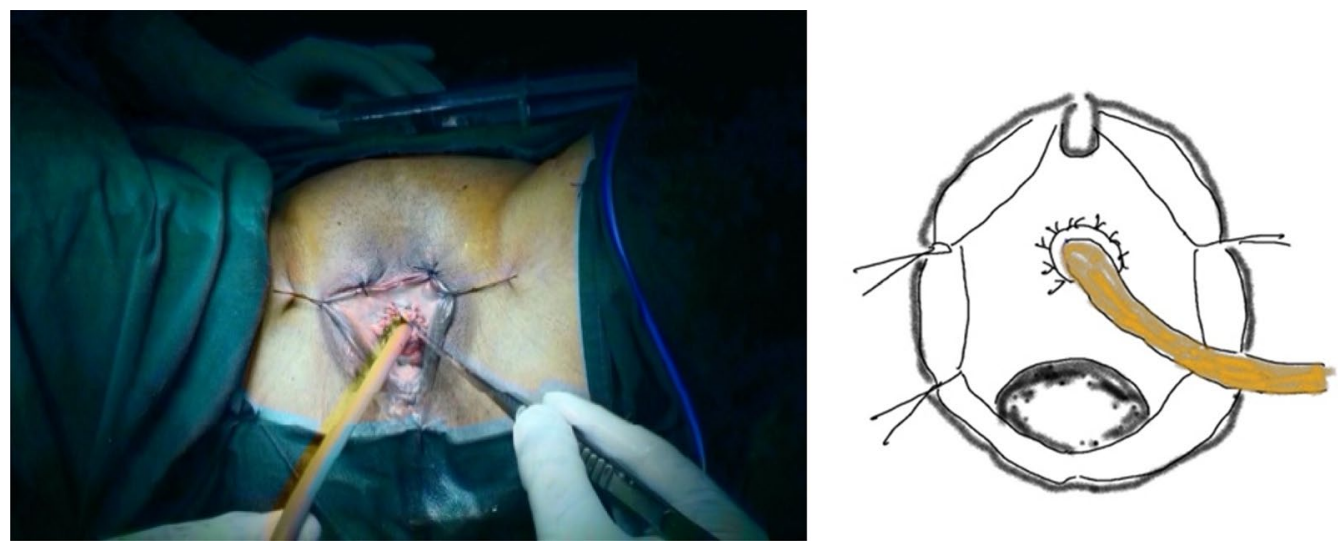

Fig. 6 Completed meatal reconstruction

value of $<0.05$ was considered significant. Statistical analysis was done by R-Statistical software version 3.5.1.

\section{Results}

We identified twenty-four patients who underwent dorsal vaginal graft urethroplasty by a single surgeon for urethral stricture disease. The mean age of our cohort was 46.54 years (range 38-55 years), and the mean follow-up period was 22.62 months (range 12-36 months) (Table 2). Nineteen of the 24 patients had $>24$ months of follow-up. The strictures were idiopathic in all the cases.

Self-reporting QOL score using the PGI-S showed that twenty out of 24 women graded their symptoms as class 4 (severe) and four patients as class 3 (moderate). In eighteen patients (75\%), the strictures were located in the middle one-third of the urethra, while only six $(25 \%)$ had both proximal and distal urethral involvement. The mean stricture length was $1.32 \mathrm{~cm}$ (range $0.8-1.8 \mathrm{~cm}$ ). Four of the 24 patients had preoperative urethral calibration size of $<\mathbf{1 0 ~} \mathbf{~ F}$ while eight calibrated at $12 \mathrm{~F}$. Ten women calibrated to $14 \mathrm{~F}$ while the remaining two women calibrated to $16 \mathrm{~F}$. Twenty-one of the 24 women had prior urethral dilatation and were performing CISC. There were no history of preoperative stress or urge incontinence. Eighteen of the 24 women had preoperative urinary urgency and frequency. Sixteen of them had their symptoms resolve after the surgery, while two continued to experience irritative symptoms. There was no history of new-onset urinary urgency after the procedure. Also, three of the 24 women had a history of recurrent UTIs before surgery, which was resolved after the operation. There was no incidence of postoperative new-onset UTIs.

The mean (range) and median (IQR) preoperative urethral calibration size of our cohort were $12.67(6-16) \mathrm{F}$ and 13 (2) F, respectively, while the mean (range) and median (IQR) postoperative calibration size were 24.50
(22-28) F and 24 (2) F; the improvement (median $12 \mathrm{~F}$ ) is significant $(p<0.05)$. The mean (range) and median (IQR) preoperative Qmax were $6.35(3.8-8.4) \mathrm{ml} / \mathrm{s}$ and $6.65(1.85) \mathrm{ml} / \mathrm{s}$, respectively, whereas the mean (range) and median (IQR) postoperative Qmax were 25.12 $(19.6-30.4) \mathrm{ml} / \mathrm{s}$ and $25.80(3.35) \mathrm{ml} / \mathrm{s}$, respectively; the improvement (median $18.8 \mathrm{ml} / \mathrm{s})$ is significant $(p<0.05)$. Similarly, the mean (range) and median (IQR) preoperative PVR for our cohort were $148.12(86-200) \mathrm{ml}$ and 145 (41.75) $\mathrm{ml}$, respectively, while the mean (range) and median (IQR) PVR decreased to $41.67(10-125) \mathrm{ml}$ and $40(21.25) \mathrm{ml}$, respectively; the amount of decrease (median $105 \mathrm{ml})$ is significant $(p<0.05)$. We used the PGI-I score to assess self-reporting satisfaction after surgery. It showed that five (5) patients scored 1 (very much better), sixteen (16) patients scored 2 (much better) and three (3) patients scored 3 (a little better). No patient scored 4-7 (no change to very much worse).

The mean operative time was $87.50 \mathrm{~min}$ (range $70-120 \mathrm{~min}$ ). No patient reported any significant postoperative pain, foul urethral discharge (infection) or signs of graft necrosis (discolouration or sloughing of the graft). There was no incidence of postoperative de novo stress or urge incontinence.

At 1-year follow-up, all of the patients had satisfactory Qmax over $19 \mathrm{ml} / \mathrm{s}$ with a significant improvement in voiding and irritative symptoms. There were no reports of vaginal narrowing or Dyspareunia. Although had an adequate flow, four patients continued to have raised PVR, but without any UTI or discomfort. Although having an acceptable flow at one-year follow-up, three women started to experience poor afterwards to reach a Qmax $<10 \mathrm{ml} / \mathrm{s}$ at 18 -months follow-up. They required dilatation by their local Urologists. All of them revealed stricture recurrence at the proximal graft-urethral anastomosis on urethroscopy. However, two of them got 
stabilised with weekly soft-dilatation (by Nelaton catheter) over the next six months and did not require further intervention. The third patient experienced a short-lived response to repeated dilatations. However, she chooses to have long-term CISC over redo-surgery. All in all, according to our definition of failure, the failure rate was $12.5 \%$ (3 out of 24 cases) at a mean follow-up of 22.6 months.

All data and materials are made available through Tables 1, 2 and 3.

\section{Discussion}

Female urethral stricture (FUS) is a rare subset of female $\mathrm{BOO}$ and is often underdiagnosed. Women with FUS can experience both storage and voiding symptoms that are often complicated by recurrent UTIs. Although extreme condition like obstructive uropathy is rare, the symptoms are usually of long duration with considerable impact on the quality of life [5]. The exact aetiology of FUS is still unclear. Several authors attributed it to infection, chronic irritation, repeated prior dilatation, difficult catheterisation, urethral surgery or trauma [17, 18]. Osman et al. described FUS as: "A symptomatic, anatomical narrowing of the urethra based on a failure of catheterisation, urethral calibration, visual inspection, or endoscopy or radiography" [3]. This definition guided us to a great extent in deciding the exclusion criteria of FUS. These are meatal stenosis, primary or functional bladder neck obstruction, neurogenic bladder, pelvic irradiation, urologic or gynaecologic malignancy or trauma. Besides voiding difficulty, most of our patients also had irritative symptoms. This is consistent with the findings of Brannan [19], who reported that up to $35 \%$ of women with irritative symptoms might have variable degrees of FUS.

FUS also poses a diagnostic dilemma for the Urologists. In the absence of any strict diagnostic criteria, a combination of presenting symptoms and objective findings are often used to attain a diagnosis [5]. Since a correct preoperative diagnosis is a foundation for a right operative approach and its successful outcome, several authors tried to define female $\mathrm{BOO}$ using different urodynamics criteria. Victor W. Nitti et al. used a higher mean Pdet

Table 1 Preoperative patient variables

\begin{tabular}{|c|c|c|c|c|c|c|c|c|}
\hline SI. no & Age (years) & Presenting symptoms & Previous dilatation & Qmax (ml/s) & PVR (ml) & $\begin{array}{l}\text { Urethral } \\
\text { calibration (F) }\end{array}$ & $\begin{array}{l}\text { Location of } \\
\text { stricture/length } \\
(\mathrm{cm})\end{array}$ & PGI-S \\
\hline 1 & 47 & $P F, I C V, F U$ & Yes & 6.2 & 150 & 10 & Mid/1 & 4 \\
\hline 2 & 52 & $P F, I C V, F U$ & No & 3.6 & 200 & 6 & Mid/1.2 & 4 \\
\hline 3 & 38 & $P F, I C V, F U$ & Yes & 4.5 & 160 & 12 & Mid/1.2 & 4 \\
\hline 4 & 39 & $P F, I C V, F U$ & Yes & 6.0 & 175 & 14 & $\mathrm{Mid} / 1.3$ & 4 \\
\hline 5 & 55 & $P F, I C V, F U$ & No & 4.6 & 110 & 10 & Mid/ + Distal/1.8 & 4 \\
\hline 6 & 50 & PF & Yes & 5.2 & 130 & 12 & Mid/1 & 4 \\
\hline 7 & 46 & $P F, I C V, F U$ & Yes & 6.8 & 86 & 12 & Mid/1.1 & 4 \\
\hline 8 & 48 & $P F, I C V, F U$ & No & 7.8 & 200 & 10 & Mid/1.5 & 3 \\
\hline 9 & 52 & $P F, I C V, F U$ & Yes & 7.5 & 155 & 14 & Mid/1.4 & 4 \\
\hline 10 & 45 & $P F, I C V, F U$ & Yes, with OIU & 4.5 & 140 & 14 & Mid/1.2 & 4 \\
\hline 11 & 43 & FU & Yes & 4.2 & 124 & 14 & Mid + Distal/1.7 & 4 \\
\hline 12 & 48 & $P F, I C V, F U$ & Yes & 5.6 & 125 & 12 & Mid/1.3 & 4 \\
\hline 13 & 50 & $P F, I C V$ & Yes & 7.2 & 160 & 12 & Mid/1.2 & 3 \\
\hline 14 & 51 & $P F, F U$ & Yes & 7.0 & 180 & 16 & Mid/1.5 & 4 \\
\hline 15 & 42 & PF, Recurrent UTI & Yes & 7.2 & 120 & 14 & Mid/0.8 & 3 \\
\hline 16 & 44 & $P F, I C V, F U$ & Yes & 7.6 & 130 & 14 & $\mathrm{Mid} / 1.2$ & 4 \\
\hline 17 & 42 & $P F, I C V, F U$ & Yes & 5.8 & 124 & 12 & Mid + Distal/1.7 & 4 \\
\hline 18 & 51 & $P F, I C V$ & Yes & 6.5 & 150 & 14 & Mid + Distal/1.8 & 4 \\
\hline 19 & 43 & $P F, I C V, F U$ & Yes & 7.3 & 165 & 14 & Mid/0.8 & 4 \\
\hline 20 & 47 & $P F, I C V, F U$ & Yes & 7.5 & 130 & 14 & Mid/1.2 & 4 \\
\hline 21 & 46 & PF, ICV & Yes & 8.0 & 135 & 16 & Mid/1.3 & 3 \\
\hline 22 & 48 & PF, FU, Recurrent UTI & Yes & 8.4 & 180 & 12 & Mid + Distal/1.8 & 3 \\
\hline 23 & 52 & $P F, I C V$ & Yes, with OIU & 6.5 & 200 & 12 & Mid + Distal/1.7 & 4 \\
\hline 24 & 38 & PF, ICV, FU recurrent UTI & Yes & 7.0 & 126 & 14 & Mid/1.1 & 4 \\
\hline
\end{tabular}


Table 2 Postoperative patient variables

\begin{tabular}{|c|c|c|c|c|c|c|c|}
\hline SI. no & $\begin{array}{l}\text { Follow-up } \\
\text { (months) }\end{array}$ & $\begin{array}{l}\text { Urethral calibration } \\
\text { (F) }\end{array}$ & $\operatorname{Qmax}(\mathrm{ml} / \mathrm{s})$ & PVR (ml) & PGI-I score & $\begin{array}{l}\text { Need for } \\
\text { dilatation }\end{array}$ & $\begin{array}{l}\text { Operative } \\
\text { time (min) }\end{array}$ \\
\hline 1 & 24 & 24 & 24.4 & 20 & 2 & No & 80 \\
\hline 2 & 24 & 26 & 20.6 & 60 & 1 & No & 90 \\
\hline 3 & 24 & 24 & 19.6 & 35 & 1 & Yes & 100 \\
\hline 4 & 24 & 24 & 28.2 & 45 & 1 & No & 90 \\
\hline 5 & 36 & 24 & 20.4 & 20 & 2 & No & 80 \\
\hline 6 & 24 & 24 & 24.3 & 10 & 2 & No & 120 \\
\hline 7 & 36 & 26 & 28.4 & 30 & 2 & No & 80 \\
\hline 8 & 24 & 24 & 26.2 & 40 & 2 & Yes & 85 \\
\hline 9 & 24 & 24 & 26.5 & 50 & 3 & No & 100 \\
\hline 10 & 24 & 26 & 22.4 & 55 & 1 & No & 90 \\
\hline 11 & 24 & 28 & 24.5 & 30 & 2 & No & 80 \\
\hline 12 & 24 & 24 & 26.8 & 50 & 2 & Yes & 70 \\
\hline 13 & 24 & 26 & 30.4 & 20 & 1 & No & 85 \\
\hline 14 & 24 & 24 & 26.4 & 25 & 2 & No & 90 \\
\hline 15 & 15 & 24 & 24.0 & 40 & 2 & No & 90 \\
\hline 16 & 12 & 24 & 28.6 & 45 & 2 & No & 90 \\
\hline 17 & 24 & 26 & 28.2 & 50 & 3 & No & 100 \\
\hline 18 & 12 & 22 & 26.4 & 30 & 2 & No & 100 \\
\hline 19 & 12 & 24 & 24.7 & 40 & 2 & No & 90 \\
\hline 20 & 24 & 22 & 22.8 & 25 & 2 & No & 80 \\
\hline 21 & 12 & 26 & 19.8 & 45 & 2 & No & 70 \\
\hline 22 & 24 & 24 & 26.0 & 70 & 2 & No & 75 \\
\hline 23 & 24 & 24 & 27.8 & 125 & 2 & No & 75 \\
\hline 24 & 24 & 24 & 25.6 & 40 & 3 & No & 90 \\
\hline
\end{tabular}

$P G I$-I score patient global impression of improvement questionnaire [10]

Qmax $>42 \mathrm{~cm} \mathrm{H}_{2} \mathrm{O}$, low flow rates $<9 \mathrm{ml} / \mathrm{s}$ with a high PVR of $157 \mathrm{ml}$. for diagnosis [4]. In contrast, Defreitas G A et al. stated that a Pdet Qmax $>25 \mathrm{~cm}$ water with a flow rate of $<12 \mathrm{ml} / \mathrm{s}$ is sufficient to suggest obstruction [20]. Similarly, Chassagne et al. also used the criteria of Pdet Qmax $>20 \mathrm{~cm} \mathrm{H}_{2} \mathrm{O}$ with a Qmax $<15 \mathrm{ml} / \mathrm{s}$ to define female BOO [21].

Urethral calibration was one of the parameters used to diagnose FUS. However, the lower calibre threshold remains undefined. In 1951, Brannan et al., in his monograph, stated that the typical female urethra usually accommodates $30 \mathrm{~F}$ without difficulty and a narrowing $\leq 20 \mathrm{~F}$ usually suggests a pathological narrowing [19]. Powel and Powel et al. [17] used a $20 \mathrm{~F}$ calibre threshold for diagnosis in 1949. This value has been reduced to 16 $\mathrm{F}$ by Weinberg et al. [22]. Schwender C E B et al. [23] and Gormley et al. [18] further reduced the calibre threshold to $12 \mathrm{~F}$. We used a calibre threshold of $16 \mathrm{~F}$ as one of the selection criteria. For diagnosis, we used a combination of subjective clinical symptoms and objective signs such as uroflowmetry (Qmax), office urethral calibration, bladder ultrasound (PVR), urethroscopy and VCUG. The diagnostic criteria we adopted conform to those reported by Keegan et al. [5] and are widely accepted. However, we used VCUG infrequently as a diagnostic tool in our study. The established hallmark feature of FUS on VCUG is the finding of an abrupt narrowing of the urethra with proximal dilatation. However, our observation is that there is often an inadequate filling of the urethra with inconsistent results.

Urodynamic tests are done less frequently and selectively only to rule out bladder dysfunction in suspicious cases such as high Qmax, raised PVR, SUI or adequate urethral lumen to counsel patients regarding the prediction of failure after urethroplasty. MRI or TV-US is also done very selectively to support diagnosis and estimation of the degree of periurethral fibrosis or any other local pathology.

Successful management of FUS disease has been reported using UD and CISC with surgery being reserved for patients who have failed these minimally invasive procedures $[6,18]$.

So, it has been common among Urologists to try out UD initially, sometimes on repeated occasions, before 
Table 3 Comparison between the pre- and postoperative variables

\begin{tabular}{|c|c|c|c|c|c|c|}
\hline SI. no & $\begin{array}{l}\text { Preoperative } \\
\text { calibration (F) }\end{array}$ & $\begin{array}{l}\text { Postoperative } \\
\text { calibration (F) }\end{array}$ & Preoperative PVR (ml) & Postoperative PVR (ml) & $\begin{array}{l}\text { Preoperative Qmax } \\
(\mathrm{ml} / \mathrm{s})\end{array}$ & $\begin{array}{l}\text { Postoperative } \\
\text { Qmax (ml/s) }\end{array}$ \\
\hline 1 & 10 & 24 & 150 & 20 & 6.2 & 24.4 \\
\hline 2 & 6 & 26 & 200 & 60 & 3.6 & 20.6 \\
\hline 3 & 12 & 24 & 160 & 35 & 4.5 & 19.6 \\
\hline 4 & 14 & 24 & 175 & 45 & 6.0 & 28.2 \\
\hline 5 & 10 & 24 & 110 & 20 & 4.6 & 20.4 \\
\hline 6 & 12 & 24 & 130 & 10 & 5.2 & 24.3 \\
\hline 7 & 12 & 26 & 86 & 30 & 6.8 & 28.4 \\
\hline 8 & 10 & 24 & 200 & 40 & 7.8 & 26.2 \\
\hline 9 & 14 & 24 & 155 & 50 & 7.5 & 26.5 \\
\hline 10 & 14 & 26 & 140 & 55 & 4.5 & 22.4 \\
\hline 11 & 14 & 28 & 124 & 30 & 4.2 & 24.5 \\
\hline 12 & 12 & 24 & 125 & 50 & 5.6 & 26.8 \\
\hline 13 & 12 & 26 & 160 & 20 & 7.2 & 30.4 \\
\hline 14 & 16 & 24 & 180 & 25 & 7.0 & 26.4 \\
\hline 15 & 14 & 24 & 120 & 40 & 7.2 & 24.0 \\
\hline 16 & 14 & 24 & 130 & 45 & 7.6 & 28.6 \\
\hline 17 & 12 & 26 & 124 & 50 & 5.8 & 28.2 \\
\hline 18 & 14 & 22 & 150 & 30 & 6.5 & 26.4 \\
\hline 19 & 14 & 24 & 165 & 40 & 7.3 & 24.7 \\
\hline 20 & 14 & 22 & 130 & 25 & 7.5 & 22.8 \\
\hline 21 & 16 & 26 & 135 & 45 & 8.0 & 19.8 \\
\hline 22 & 12 & 24 & 180 & 70 & 8.4 & 26.0 \\
\hline 23 & 12 & 24 & 200 & 125 & 6.5 & 27.8 \\
\hline 24 & 14 & 24 & 126 & 40 & 7.0 & 25.6 \\
\hline
\end{tabular}

undertaking reconstructive surgery. However, repeated over-dilatation may cause scarring, rapid recurrence with increasingly dense stricture formation and the accompanying risk of recurrent infections [23, 24]. Overall, the success rate of UD has been meagre (only 47\%) [3].

We describe our approach to female urethroplasty using the suprameatal urethrolysis and lateral vaginal wall free graft in a retrospective series with a mean follow-up of 22 months. This technique was originally described by Tsivian and Sidi in 2006 [8]. All the patients included in our series presented with voiding and irritative symptoms. Twenty-one of them (87.5\%) had a history of repeated urethral dilatations with a shortlived response, and a desire for a permanent curative treatment.

Currently, female urethroplasty has become a topic of increasing attention. Multiple approaches using various free grafts (the Buccal mucosal graft, lingual mucosal graft, the vaginal graft) $[8,11,12,15,16,24]$ and local pedicled flaps (labia minora and vestibular) $[6,18]$ have been described in female substitution urethroplasty. We preferred to use the technique of dorsal suprameatal urethrolysis, because it is easy to perform as well as it provides easier access to the ventral aspect for any future anti-incontinence surgery [9]. In 1999, Petrou SP et al. originally described the technique of dorsal ureterolysis [9]. They showed that the female urethra could be dissected off from the clitoral complex without injuring the sphincter. We followed the same technique as Petrou SP et al. in performing the urethrolysis. We undertook the dorsal urethrolysis with urethrotomy as a first step before graft harvesting, because it allows the visual assessment of the severity and length of stricture which is crucial for the estimating the dimension of the graft to be taken. A critical advantage of the dorsal approach is the strong mechanical support and good vascular bed provided by 
the clitoral-cavernosal tissue, minimising the risk of a diverticulum formation [24]. Besides, the other potential advantages are an up-directed urinary stream, minimal risk of urethral hypospadias or urethra-vaginal fistula [24].

The original vaginal graft onlay technique by Tsivian and Sidi [8] influenced the subsequent researchers in choosing vaginal epithelium in urethroplasty. Vaginal graft fulfils most of the requirements of an optimal graft $[11,12]$. It is hairless, easily harvestable from the lateral vaginal wall, cosmetically sound with minimal donor-site morbidity and simple to perform (no requirement of tissue tunnelling or flap rotation). It is also a full-thickness graft with thick epithelium and high elastic fibres, naturally wet and infection-resistant. The procedure can easily be done under spinal anaesthesia avoiding general anaesthesia or nasotracheal intubation. Demerits of vaginal graft are the potential risk of vaginal narrowing and Dyspareunia. When there is vaginal mucosal atrophy or vaginal stenosis, the graft quality suffers, and harvesting is difficult. Labial grafts were used in three studies also showed similar results [13-15]. To avoid the potential risk of vaginal donor site morbidity and other demerits, several authors have started using the buccal mucosal graft (BMG) instead [24-29]. The success rate has been reported as slightly higher $(94 \%)$ compared to the vaginal graft series (80\%) [3]. However, the risk of oral donor site morbidity and requirement of general anaesthesia are the demerits of BMG.

We identified four studies where vaginal mucosa was used as onlay graft during female urethroplasty $[8,11$, 12, 16]. Steven P. Petrou et al. reported the use of DVGU using Tsivian and sidi's approach of dorsal urethrolysis [11]. The stricture-free rate was $73 \%$ after a mean follow-up of 22.7 months. There was no incidence of new-onset stress incontinence. The author opined that in the absence of a clear consensus on the ideal reconstructive approach, the dorsal vaginal graft (VG) urethroplasty could be used as a first-line approach. Singh $\mathrm{M}$ et al., in their retrospective review of 16 women with mid-urethral strictures, reported their experience of DVGU with $100 \%$ success rate over a mean follow-up of 24.5 months [12]. No incidence of de novo incontinence was reported in this series. Onol et al. shared their experience of urethroplasty on 17 women [13]. Of the 17 patients, 10 received anterior vaginal wall mucosa inlay urethroplasty, whereas two patients received ventral onlay BMG reinforced by Martius flap and another two, a dorsal onlay BMG and the remaining two, a circular BMG reconstruction. The objective and subjective cure rate have been achieved in 17 (100\%) and 15
(88\%) women, respectively, over a median follow-up of 24 months. The authors concluded that primary urethroplasty could be considered as a first-line option for the treatment of FUS. The only prospective series till date in FUS has been credited to Manasa et al. [16]. However, it had the shortest mean follow-up of only 8.5 months. They also reported about the sexual dysfunction issues in women with FUS. This paper cited a $77 \%$ overall success rate, with an improvement in female sexual function inventory (FSFI) score by 6.42 points. Overall, in the four studies (total 42 patients) using vaginal graft, the mean success rate was $87.48 \%$ with a mean followup of 24.83 months. In all the four studies, the graft was placed by dorsal onlay technique at 12 "O clock position (Table 4).

Despite using short-term data of only 24 cases, the success rate of our series is very competitive to other similar approaches (Table 4). No patients in our series needed to perform postoperative CISC as part of their treatment plan as in other series [18]. Only three of our 24 patients (12.5\%) had a recurrence of symptoms. Thus, strictly following our definition of failure, there was $12.5 \%$ failure at a mean follow-up of 22.62 months. However, we observed some correlation between the preoperative urethral calibre and the need of the postoperative dilatation. All the three recurrences had their initial urethral calibre less than $12 \mathrm{~F}$. This observation may assist us in setting patient expectation regarding the operative outcome. We acknowledge that urodynamics could have better been able to diagnose and document female $\mathrm{BOO}$ and help predict the post-urethroplasty failure rate. Further work on this topic is necessary for the future. Still, those are also expected to be in the form of similar case series only, as FUS is rare and most of the patients initially refuse to undergo reconstructive surgery. Dilatation with CISC will continue to remain the initial approach, at least for the present, till patients themselves insist for a permanent cure in the form of definitive surgery. In this context, a clear communication between the patient and surgeon is essential before undertaking such a definitive approach.

We acknowledge that this is a relatively small retrospective series (a level 4 evidence) with a shorter follow-up of 22.6 months. It may be argued that such short-term data might not detect further deterioration of graft and future re-stricture rate. However, the shortterm results in terms of patient satisfaction and the overall outcome are encouraging. This study will support and contribute to the results of other similar vaginal graft series. 
Table 4 Female urethroplasty (vaginal and labial graft) series

\begin{tabular}{|c|c|c|c|c|c|c|c|c|c|}
\hline Study & $\begin{array}{l}\text { No. of } \\
\text { Patients }\end{array}$ & $\begin{array}{l}\text { Previous } \\
\text { intervention }\end{array}$ & Technique & $\begin{array}{l}\text { Concomitant } \\
\text { procedure }\end{array}$ & Postop ISC & $\begin{array}{l}\text { Stricture- } \\
\text { free } \%\end{array}$ & $\begin{array}{l}\text { Mean } \\
\text { follow-up } \\
\text { (months) }\end{array}$ & $\begin{array}{l}\text { De novo } \\
\text { incontinence }\end{array}$ & $\begin{array}{l}\text { Other } \\
\text { complications }\end{array}$ \\
\hline $\begin{array}{l}\text { Tsivian and } \\
\text { Sidi [8] }\end{array}$ & 2 & Dilatation (all) & $\begin{array}{l}\text { Vaginal graft } \\
\text { Dorsal Onlay }\end{array}$ & No & No & 100 & 27 & No & No \\
\hline $\begin{array}{l}\text { Petrou et al. } \\
\text { [11] }\end{array}$ & 11 & Dilatation (all) & $\begin{array}{l}\text { Vaginal graft } \\
\text { Dorsal Onlay }\end{array}$ & No & No & 73 & 23 & No & No \\
\hline $\begin{array}{l}\text { Singh et al. } \\
\text { [12] }\end{array}$ & 16 & $\begin{array}{l}\text { Dilatation } \\
\text { (13) } \\
\text { Urethrotomy } \\
\text { (3) }\end{array}$ & $\begin{array}{l}\text { Vaginal graft } \\
\text { Dorsal Onlay }\end{array}$ & No & No & 100 & 24.5 & No & No \\
\hline $\begin{array}{l}\text { Önol et al. } \\
\text { [14] }\end{array}$ & 7 & $\begin{array}{l}\text { Dilata- } \\
\text { tion + Ure- } \\
\text { throtomy (5) } \\
\text { Cystostomy } \\
\text { tubes (2) }\end{array}$ & $\begin{array}{l}\text { Labia minora } \\
\text { graft } \\
\text { Ventral Inlay }\end{array}$ & No & No & 86 & 18.2 & No & No \\
\hline $\begin{array}{l}\text { Gozzi et al. } \\
\text { [13] }\end{array}$ & 4 & Dilatation (all) & $\begin{array}{l}\text { Labial graft } \\
\text { Ventral } \\
\text { approach }\end{array}$ & No & No & 100 & 15 & No & No \\
\hline $\begin{array}{l}\text { Rehder et al. } \\
\text { [15] }\end{array}$ & 8 & $\begin{array}{l}\text { Dilatation (all) } \\
\text { Meatoplasty } \\
\text { (1) }\end{array}$ & $\begin{array}{l}\text { Labial graft } \\
\text { Ventral } \\
\text { approach }\end{array}$ & No & No & 75 & 24 & No & NO \\
\hline $\begin{array}{l}\text { Manasa et al. } \\
\text { [16] }\end{array}$ & 13 & Dilatation (all) & $\begin{array}{l}\text { Vaginal graft } \\
\text { Dorsal Onlay }\end{array}$ & No & No & 76.92 & 8.5 & No & No \\
\hline Our study & 24 & Dilatation (all) & $\begin{array}{l}\text { Dorsal } \\
\text { Vaginal } \\
\text { Graft } \\
\text { Onlay }\end{array}$ & No & No & 87.5 & 22.62 & No & No \\
\hline
\end{tabular}

\section{Conclusion}

Dorsal onlay vaginal graft urethroplasty (DVGU) represents a simple surgical technique with good reproducibility and an effective low-morbidity reconstructive surgery for FUS. The present experience shows that DVGU has the potential to prove as one of the simple one-time curative options with a high success rate in female urethral stricture disease, which is often considered a difficultto-manage problem requiring repeated dilatations and CISC.

\section{Abbreviations}

LUTS: Lower urinary tract symptoms; Qmax: Peak uroflow; Pdet Qmax: Detrusor pressure at peak flow; VCUG: Voiding cystourethrography; QOL: Quality of life; PGI-S: Patient global impression of severity Questionnaire; PGI-I: Patient global impression of Improvement Questionnaire; BOO: Bladder outlet obstruction; UTI: Urinary tract infection.

\section{Acknowledgements}

I acknowledge the contribution of the whole of the team of ChM Urology course of Edinburgh University for their support during my study and designing the project on 'Dorsal Vaginal Graft Urethroplasty'. Patient data and analysis are part of the ChM project, as mentioned above. I am grateful to the Edinburgh Urology team for granting me necessary permission to publish the materials in a Journal.

\section{Authors' contributions}

JNC (First and Corresponding author) is responsible for the acquisition of data, designing, drafting and interpretation. NV (Second author) guided the first author in every step in drafting the manuscript and substantively revising it. All the authors have read and approved the manuscript.

\section{Funding}

This study is self-funded, and no external funding source is used in this study.

\section{Availability of data and materials}

Patients' data are available with the corresponding author and are already made available in the tables of the manuscript.

\section{Declarations}

\section{Ethics approval and consent to participate}

Even though it is a retrospective study and Ethics committee approval is not mandatory for our country, Institutional review board approval (Ethics committee, Apollo Hospital, Guwahati, India) was taken before this study, keeping in mind the requirements of international journals. The committee's reference number is 001/2020. Also, informed consent from all the patients concerned was taken in prescribed format before surgery for publication purpose.

\section{Consent for publication}

Written and informed consent for publication is taken from the individual patients from whom the images are taken and used in this article. 


\section{Competing interests}

The authors declare that they have no competing interests.

\section{Author details}

${ }^{1}$ Apollo Hospitals, Guwahati, India. ${ }^{2}$ SMS Medical College, Jaipur, India.

Received: 29 August 2020 Accepted: 5 March 2021

Published online: 12 March 2021

\section{References}

1. Carr LK, Webster GD (1996) Bladder outlet obstruction in women. Urol Clin N Am 23(3):385-391

2. Groutz A, Blaivas JG, Chaikin DC (2000) Bladder outlet obstruction in women: definition and characteristics. Neurourol Urodyn Off J Int Cont Soc 19(3):213-220

3. Osman NI, Mangera A, Chapple CR (2013) A systematic review of surgical techniques used in the treatment of female urethral stricture. Eur Urol 64(6):965-973

4. NITTI et al (1999) Diagnosing bladder outlet obstruction in women. J Urol 161(5):1535-1540

5. Keegan KA, Nanigian DK, Stone AR (2008) Female urethral stricture disease. Curr Urol Rep 9(5):419-423

6. Santucci RA, Payne CK, Saigal CS (2008) Urologic diseases in america project office dilation of the female urethra: a quality of care problem in the field of urology. J Urol 180(5):2068-2075

7. Wu JN, Stone AR. Female urethral stricture disease: diagnosis and management. AUA Update Series 2011: Volume 30. Lesson 7: 16 - 19. AUA Office of Education. 2011

8. Tsivian A, Sidi AA (2006) Dorsal graft urethroplasty for female urethral stricture. J Urol 176(2):611-613

9. Petrou SP, Brown JA, Blaivas JG (1999) Suprameatal transvaginal urethrolysis. J Urol 161(4):1268-1271

10. Yalcin I, Bump RC (2003) Validation of two global impression questionnaires for incontinence. Am J Obstet Gynecol 189(1):98-101

11. Petrou SP, Rogers AE, Parker AS, Green KM, McRoberts JW (2012) Dorsal vaginal graft urethroplasty for female urethral stricture disease. BJU Int 110(11c):E1090-E1095

12. Singh M, Kapoor R, Kapoor D, Kapoor R, Srivastav A, Chipde S (2013) Dorsal onlay vaginal graft urethroplasty for female urethral stricture. IJU J Urol Soc India 29(2):124

13. Önol FF, Önol ŞY, Tahra A, Boylu U (2014) Ventral inlay labia minora graft urethroplasty for the management of female urethral strictures. Urology 83(2):460-464

14. Gozzi C, Roosen A, Bastian PJ, Karl A, Stief C, Tritschler S (2011) Volar onlay urethroplasty for reconstruction of female urethra in recurrent stricture disease. BJU Int 107(12):1964-1966
15. Rehder P, Glodny B, Pichler R, Exeli L, Kerschbaumer A, Mitterberger MJ (2010) Dorsal urethroplasty with labia minora skin graft for female urethral strictures. BJU Int 106(8):1211-1214

16. Manasa T, Khattar N, Tripathi M, Varshney A, Goel H, Sood R (2019) Dorsal onlay graft urethroplasty for female urethral stricture improves sexual function: Short-term results of a prospective study using vaginal graft. IJU J Urol Soc India 35(4):267

17. Powell NB, Powell EB (1949) The female urethra: a clinico-pathological study. J Urol 61(3):557-567

18. Gormley EA (2010) Vaginal flap urethroplasty for female urethral stricture disease. Neurourol Urodyn 29(S1):S42-S45

19. Brannan D (1951) Stricture of the female urethra. J Urol 66(2):242-253

20. Defreitas GA, Zimmern PE, Lemack GE, Shariat SF (2004) Refining diagnosis of anatomic female bladder outlet obstruction: comparison of pressure-flow study parameters in clinically obstructed women with those of normal controls. Urology 64(4):675-679

21. Chassagne S, Bernier PA, Haab F, Roehrborn CG, Reisch JS, Zimmern PE (1998) Proposed cutoff values to define bladder outlet obstruction in women. Urology 51(3):408-411

22. Weinberg SR, Kovetz A, Bertoni G, Bertoni M (1973) Urethroplasty of female distal urethra. Urology 1(6):589-591

23. Schwender CE, Ng L, McGuire E, Gormley EA (2006) Technique and results of urethroplasty for female stricture disease. J Urol 175(3):976-980

24. Migliari R, Leone P, Berdondini E, De Angelis M, Barbagli G, Palminteri E (2006) Dorsal buccal mucosa graft urethroplasty for female urethral strictures. J Urol 176(4):1473-1476

25. Berglund RK, Vasavada S, Angermeier K, Rackley R (2006) Buccal mucosa graft urethroplasty for recurrent stricture of female urethra. Urology 67(5):1069-1071

26. Sharma GK, Pandey A, Bansal H, Swain S, Das SK, Trivedi S, Dwivedi US, Singh PB (2010) Dorsal onlay lingual mucosal graft urethroplasty for urethral strictures in women. BJU Int 105(9):1309-1312

27. Mukhtar BM, Spilotros M, Malde S, Greenwell TJ (2017) Ventral-onlay buccal mucosa graft substitution urethroplasty for urethral stricture in women. BJU Int 120(5):710-716

28. Hampson LA, Myers JB, Vanni AJ, Virasoro R, Smith TG III, Capiel L, Chandrapal J, Voelzke BB (2019) Dorsal buccal graft urethroplasty in female urethral stricture disease: a multi-center experience. Transl Androl Urol 8(Suppl 1):S6

29. Gomez RG, Segura FJ, Saavedra A, Campos RA (2019) Female urethral reconstruction: dorsal buccal mucosa graft onlay. World J Urol 21:1-8

\section{Publisher's Note}

Springer Nature remains neutral with regard to jurisdictional claims in published maps and institutional affiliations.

\section{Submit your manuscript to a SpringerOpen ${ }^{\circ}$ journal and benefit from:}

- Convenient online submission

- Rigorous peer review

- Open access: articles freely available online

- High visibility within the field

- Retaining the copyright to your article

Submit your next manuscript at $\boldsymbol{\nabla}$ springeropen.com 